\title{
How should economics view the Internet?
}

Economics' view of the Internet

\author{
Li Tao \\ School of Economics, Central University of Finance and Economics, Beijing, China
}

\begin{abstract}
Purpose - The study aims to elaborate the author's basic viewpoints on how economics should view the Internet from four aspects.

Design/methodology/approach - This paper reviews the existing literature on this topic, and summarizes key findings and conclusions of these researches.

Findings - The findings include four major contradictions in economics brought by the Internet, and 12 new changes in economics that needs to be addressed.

Originality/value - This paper provides a clear summary of existing studies on economics' views of the internet and a prospect for future internet economy research.
\end{abstract}

Keywords Internet technology, Internet economy, Digital economy, Economic research

Paper type Research paper

\section{Introduction}

Before exploring the relationship between the Internet and economic research, we first need to precisely understand the correlations and differences between the Internet and digit. Do we really understand and distinguish the concepts of those two terms - Internet and digit? The Internet actually is no stranger to everyone, and in my opinion, it is a part of the human network, an upgraded version 2.0 that can connect the global computer networks through a set of general protocols.

Regarding digit, I would like to clarify a misconception that digit and data are often mixed. In fact, the definition of data is relatively broad: data are the carrier of information and a new production factor. Its manifestations can be text, sound, image and so on. Digit is part of the data, a version 2.0 of the data that can be stored and operated on in a $0-1$ binary form on a computer system. Therefore, according to my understanding, the similarities between the Internet and digit lie in the fact that they are both the way of existence and the mode of operation after the development of human society to a certain stage, while the difference lies in the fact that the Internet places more emphasis on "connection and interaction"-with the characteristics of external compatibility, fluidity and diversity, while digit places more emphasis on "storage and operation"-with the characteristics of internal security, granulation and formatting.

\section{Four contradictions}

Regarding the challenges brought by the Internet to the traditional economic research, I generalize and summarize them into the following four contradictions:

(C) Li Tao. Published in Journal of Internet and Digital Economics. Published by Emerald Publishing Limited. This article is published under the Creative Commons Attribution (CC BY 4.0) licence. Anyone may reproduce, distribute, translate and create derivative works of this article (for both commercial and non-commercial purposes), subject to full attribution to the original publication and authors. The full terms of this licence may be seen at http://creativecommons.org/licences/by/4.0/legalcode

This paper is supported by Beijing Outstanding Young Scientist Program (BJJWZYJH01201910034034) and National Social Science Foundation Fund (18AZD007).

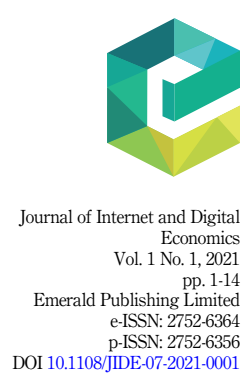


JIDE

First is the contradiction between "Slow" and "Fast". The Internet is the most far-reaching technological, economic and social phenomenon witnessed by human civilization so far, along with the most rapid development, the most intense competition, the most active innovation, the most universal participation and the most extensive penetration. However, theoretical research on the Internet and the digital economy falls behind by more than one position compared with the Internet industry which "travels thousands of miles per day". Economic studies require the precipitation of time and knowledge, the in-depth elaboration of theoretical basis and the full verification of general laws. Economics focus on the study of laws that have settled down and are stable and unchangeable over time, while the changes of the Internet can be described as changing with each passing day. Therefore, our first contradiction is to find the "slow" law from the "fast" change.

Second is the contradiction between "Old" and "New". As the leading force driven by technological progress and innovation, the Internet is witnessing the continuous emergence of new technologies and platforms, which has given birth to a series of new phenomena and problems. What we are used to is still the traditional research methods and research paradigms, but what we are solving now are new problems in the fields of the Internet and digit. Obviously, we cannot stand in the past and look at the future. Instead, we must stand in the future and look at the present. The contradiction manifests itself in the study of "new" problems in the "old" environment.

Third is the contradiction between "Universal" and "Unique". Traditional economics is based on industrial society and pursues the universality of laws and conclusions, such as profit maximization and diminishing marginal returns. In the Internet era, the heterogeneity of users and the uncertainty of information acquisition are fully considered, and more emphasis is placed on uniqueness and specificity to find personalized evidence. The contradiction is to find and extract the universal laws from unique image.

Fourth is the contradiction between "Virtual" and "Real". Traditional economics mainly focuses on the real economy, and the basic theoretical foundation is the scarcity of resources. The rise of Internet economy reflects the prosperity of virtual economy. The classic assumption of scarcity is challenged because digital goods and services can be duplicated almost at zero cost. Therefore, the contradiction is mainly reflected in the problem of how to redefine "real" scarcity in the "virtual" abundance.

\section{Changes that the Internet brought to current economic research}

What changes has the Internet brought to current economic research? I summarize the impacts of the Internet on economic research as twelve "New" changes. According to the logic of upgrading from micro level to macro level, the changes include the following:

\subsection{New knowledge}

Internet-based information exchange and content creation are important sources of new knowledge and understanding. Information reflects the state of things moving and its changing ways, while knowledge explores the state of things moving and its changing laws. Knowledge can only be acquired through the processing of information (Zhang, 2011). The development of information economy is based on the digital coding of information and knowledge, with digital resources as the core factor of production and the Internet as the main carrier. On the one hand, the existing knowledge can be quickly spread through the Internet. On the other hand, new technology applications such as Internet-based cloud computing, the Internet of things, big data, artificial intelligence, virtual reality and new formats such as platform economy and sharing economy have spawned new forms of information and knowledge. For example, artificial intelligence can be regarded as a tool for ideological experiments to construct the hypothetical world needed by theories and thus test the correctness of economic theories (Du and Cheng, 2020). 
The widespread use of information technology has accelerated the codification of knowledge, thus facilitating the spillovers of integrated innovation (Varian, 2010). By extracting and analyzing the data information and using it to improve the algorithm, display the product information to the users and realize the real-time measurement of the results, the information can be mined in depth to form valuable knowledge. For example, data from user search records can be used to predict trends in various economic activities, such as car purchases, real estate transactions, retail trade, travel and tourism, and employment (Choi and Varian, 2012). The Internet has promoted the sharing of knowledge, payment of knowledge and transactions of intellectual property rights to become a social consensus. In the Internet era, emphasis is placed on improving the creation and output of knowledge rather than simply maximizing profits. It encourages the realization of the value of knowledge economy through knowledge sharing and collaboration. Collaboration is the main feature of knowledge production activities in the digital era. Through the network platform, knowledge modules from different fields are gathered and connected together through hyperlinks to form a knowledge production and learning network, which improves the learning efficiency.

\subsection{New skills}

The application of the Internet and digital technology has greatly improved people's abilities in daily work, information search, communication with the outside world and innovation. First of all, the Internet has played a huge role in promoting work efficiency (Akerman et al., 2015). As a medium of interconnection, the Internet helps people to communicate and learn at any time and place, which drive people to learn and master new Internet technologies, such as intelligent and real-time work systems. The use of digital technologies, such as data, cloud computing, artificial intelligence, block chains and industrial Internet, has greatly freed up human and material resources and greatly improved labor productivity relying on digitalization. Secondly, in the past, the flow of information flow was limited by geography, and people's access to information was limited to some areas around them. The development of the Internet, accompanied by the popularity of social tools such as mobile phones, WeChat and Weibo, has expanded people's access to information and significantly improved people's ability to make decisions based on information (Kroft and Pope, 2014).

The collection of information also plays an important role in firm's production process or in its production decision-making process. Economics believes that the asymmetry of information will lead to the decrease of efficiency - when the decision-maker is faced with severe information asymmetry, many deviations will appear in the decision-making. The emergence of the Internet has greatly alleviated the problem of information asymmetry. Thanks to Internet technology, information can be gathered to help enterprises make wise decisions and thus improve their operation and management capabilities. At the same time, from the interconnection of everyone to the interconnection of everything, the emergence of the Internet has expanded people's channels of communication with the outside world and increased people's opportunities to contact with the outside world (Wang and Wang, 2016).

The development of Internet technology has significantly reduced the cost of service delivery over a long distance, fundamentally reshaped the inefficient and non-tradable nature of the traditional service industry and greatly strengthened the driving force of the globalization of services. Finally, the emergence of the Internet has promoted a new pattern of "mass entrepreneurship and mass innovation", improved matching efficiency of the market through digital platforms, and given new momentum to people's willingness and ability to innovate (Naude and Liebregts, 2020). As a new organizational form to adapt to the capital accumulation and social production and reproduction of the digital technology system, the platform economy relies on a digital platform supported by an efficient data collection and transmission system, developed computing power and powerful data processing algorithms
Economics' view of the Internet 
$\underset{1,1}{\text { JIDE }}$

to integrate social production, distribution, exchange and consumption activities across time and space and across departments, thus greatly promoting the development of social productive forces.

\subsection{New feelings}

Although the Internet can be regarded as a neutral technology, the impact it brings to people's subjective emotions and feelings should not be ignored. Overall, the influence has both positive and negative aspects.

The main manifestations of positive emotions include the following: (1) happiness: the information welfare through using the Internet significantly improves people's subjective well-being (Lu and Wang, 2020). The diffusion of digital technology in the elderly is positively correlated with higher quality of life, higher life satisfaction, less loneliness and less depressive symptoms. When the elderly successfully master Internet skills, they tend to be more satisfied and confident with themselves and better integrated into the society (Chopik, 2016). (2) Sense of convenience: the emergence of the Internet has remarkably facilitated all aspects of people's daily life. The emergence of services such as electronic payment and online shopping allows people to enjoy the convenience digital technology brings to life (Chechina and Nikonorova, 2019). (3) Sense of social participation: in the "pre-Internet" era, there is often a serious information asymmetry or "lagging knowledge" about the process and truth of social events in the public domain. The Internet has endowed the public with more rights to express, disseminate and know. By leaving messages on the Internet, individual participation in collective actions has been greatly strengthened (Katz and Rice, 2002). In a series of natural disasters or traffic accidents in recent years, the uninterrupted information transmission gathered by mobile social platforms and the resulting collective actions such as rescue and fund-raising have become the forces that can be relied on to deal with emergencies. (4) Sense of achievement: taking the e-commerce poverty alleviation as an example, by reducing the intermediate circulation links and improving the matching efficiency, it has promoted the rise of farmers' income and the residents' sense of access in poor areas (Wang, 2019).

The main manifestations of negative emotions include the following: (1) sense of network disorder: the Internet brings convenience to people's life, but at the same time, the offensive remarks and emotional catharsis caused by its unorganized and anonymous nature have a negative impact on the order of the network environment and even social stability. For example, online discourse violence or group irrationality in reality-the former will cause extreme voices to expel benign speech with a tough attitude, thus forming "group polarization"; The latter is an extension of the phenomenon of group polarization at the practical level, and behind many group events are social media (Mossberger et al., 2007). (2) Sense of insecurity: many governance challenges brought by the Internet harm people's sense of security. As a new technology, the Internet brings great convenience for information dissemination, but also results in a series of social problems like cybercrime. All kinds of such potential risks impact public sense of security to a certain extent (Sun et al., 2020). The emergence of cyber virtual space has given birth to new criminal opportunities. The difficulties in collecting, examining and identifying digital evidence, coupled with the lag of legislation, have exacerbated public anxiety. At the same time, communication in the Internet context lacks tangible elements such as face-to-face communication, which makes it more difficult to build trust in the Internet context (Grabner-Kraeuter, 2002). How to effectively govern the virtual Internet space is an urgent task for all countries over the world.

\subsection{New concepts}

As the Internet enters people's lives, it also exerts a subtle influence on people's consumption concepts and social perceptions. The concrete manifestation includes the following: 
Market view: with the rapid expansion of online market transactions and the convergence of online and offline markets, the role of market economy in the Internet era is more dynamic and more recognized (Levin, 2011). Furthermore, when people can learn about other people's behaviors on the Internet, following the market trend is more likely to be the optimal choice of the people, as people believe that these behaviors are the integrated information filtered by other people's wisdom, and the market signals are of great significance. Aggregation through the Internet may magnify the importance individuals attach to the market (Jiang, 2017).

Consumption concept: online payment tools such as Alipay and Wechat have been widely used, non-cash transactions have developed rapidly, and self-help consumption has become popular. According to statistics from China Internet Network Information Center (CNNIC), the scale of online shopping transactions in China increased from 0.51 trillion yuan in 2010 to 11.76 trillion yuan in 2020, and more than half of Chinese participated in online shopping. The prosperity of online shopping indicates that online consumption is gradually taking the place of offline consumption, and also online credit consumption has become the norm.

Investment view: information technologies such as mobile Internet, cloud computing and big data are advancing by leaps and bounds, which has promoted the development of Internet finance and financial technology, thus changing people's investment and financial concepts and habits (Bogan, 2008). With Internet financial services, investors can easily and quickly switch between various products, thus realizing the personalized investment portfolio. By the end of 2017, the total transaction volume of China's Internet financial products had reached nearly 15 trillion yuan, which was close to $20 \%$ of the total GDP of that year. Residents no longer simply deposit their money in the bank but invest on different kinds of products online instead. The emergence of the Internet has enriched people's investment channels, and people's financial awareness and concept become more active. In particular, the expansion of Internet finance in rural areas eases the cost constraints faced by rural financial services in the past, leads to the improvement of credit services for rural areas and contributes a lot to the implementation of the Inclusive Financing concept (Huang, 2018).

Entrepreneurial view: with the information welfare and transaction convenience brought by the Internet, everyone can participate in digital entrepreneurship through the combination of digital technology, electronic commerce and entrepreneurship (Naude and Liebregts, 2020). Dillon et al. (2020) examines how entrepreneurs gain international experience in a digital business environment and analyses how entrepreneurs refer to the information to identify international opportunities. Research shows that entrepreneurs who use digital technology to communicate in an international environment may promote the emergence of a new kind of experience: "digital internationalization experience". In turn, this new experience helps boost creativity and the ability to seize opportunities which are crucial for digital entrepreneurship.

Sharing view: sharing is an Internet culture and also the basic purpose of the development of the Internet. Openness and cooperation in the Internet field help all parties to complement each other and share the profit of development. Sharing economy is a typical feature of the Internet age. As a new economic growth point in the digital era, the development prospect of shared economy is immeasurable (Horton and Zeckhauser, 2016).

Concept of democracy and the rule of law: on the one hand, the Internet has promoted the whole society's concept of democracy and the rule of law through its advantages in information disclosure and dissemination. On the other hand, it also has a certain impact on the concept and system of a country, especially the concept of state sovereignty and the basic state functions derived from it, which are mainly manifested in the control over individuals, the judicial ability, the tax jurisdiction, the country's position in international relations and the challenge to the security ability (Zhou and Zhou, 2001). In addition, the emergence of new patterns such as Internet politics has reduced the cost of public participation in social governance and promoted the update of the public participation awareness in government decision-making (Meng and Huang, 2019).

Economics' view of the Internet 


\section{JIDE 1,1}

\subsection{New products}

With the continuous growth of digital industrialization, we are exposed to a growing number of new digital products in the market (Leung and Lee, 2005). The representative product categories include the following:

Products for transaction: this product form aims at meeting the needs derived from various types of online transactions. Its business content includes the purchase and sale of physical goods, virtual goods and various services, with business patterns including B2B, $\mathrm{B} 2 \mathrm{C}, \mathrm{C} 2 \mathrm{C}$ and derivative $\mathrm{O} 2 \mathrm{O}$, etc.

Products for social: this product form mainly aims at meeting people's social needs derived from daily life. In a broad sense, it includes various Internet products related to information interaction among people within a family, a community, or a group. Products for social can also be subdivided based on different dimensions, such as acquaintances and strangers depending on whether they know each other; words, voice, pictures, videos, etc, as different forms of social media, and regions, contacts and interests as the characteristics of users.

Products of content: this product form mainly introduced to meet users' demand for information acquisition. Unlike products for social, which downplay the role of users and emphasize information interaction, products of content usually have obvious content producers and consumers.

Products of tools: this product form is primarily designed to address the immediate needs of users in a specific environment. Such products often have clear requirements and relatively simple product logic. As users usually have a strong purpose, they only use the products when they have to use them. Therefore, the number of users may be high but it is difficult to dig the commercial value and find the ways to realize it.

Platform-based products: different from the above-mentioned types of products, platformbased products are usually designed to meet the needs of users across various aspects, which are relatively integrated and complicated. This kind of product usually focuses on a single target in the initial stage, and then it continuously expands to relevant business areas and eventually forms an ecological platform product. For example, WeChat has evolved from a single communication tool to a comprehensive online platform that integrates multiple functions of transaction (WeChat Pay), social (Group Chats, Moments), content (Official Accounts) and tools (Mini Programs).

\subsection{New services}

The combination of the Internet and the traditional service industry has spawned a series of new service industries, such as smart medical care, smart education, smart transportation, smart finance and various sharing services (Barrett et al., 2015). For example, the intelligent transportation model based on cloud computing, big data and other new generation technologies can effectively solve the transportation dilemma in the urban development and fully meet the travel demand of the public.

With the development of mobile Internet, the Internet of things, big data, intelligent identification and other technologies, self-driving technology can independently identify the driving environment, combine the user requirements with the intelligent transportation network system to set the best traveling route and automatically control the vehicle to travel. In particular, intelligent services based on digital technology have played an irreplaceable role in China's successful response to the impact of the COVID-19 epidemic. For example, some platforms like Meituan implemented "contactless delivery" to substitute the previous "hand-to-hand" delivery model and avoid face-to-face contact. When placing an order, the user can negotiate with the deliveryman for a designated place to place the food, such as the front desk of the company or the door of the apartment, through the "order note", telephone, or APP message system. After delivery, the user will be notified to take his own meal with a 
massage. As another example, in the situation of travel restrictions, "VR plus travel" is a new form of travel accepted by more and more people. In all major scenic spots and theme parks, VR experience shops are emerging one after another. Consumers can enjoy the fun of cloud travel through VR headsets, mobile phones, computers and other digital devices. In addition, with the decline of the demographic dividend, the new service model of "replacing labor with machine" supported by artificial intelligence technology has become a trend, and technologies such as service robots and intelligent voice recognition have improved the service quality and efficiency.

\subsection{New components}

The development of the Internet and the digital economy naturally breed a group of new components that will lead the economic and social development. At the industry level, some new players have emerged, such as express delivery in the logistics industry, electronic payment in the financial industry, take-out in the catering industry, online education in the education industry, cloud healthcare in the medical industry, targeted delivery in the advertising industry, etc.

On the individual level, on the one hand, in terms of consumption pattern, with the development of online shopping, the main body of household daily consumption has gradually expanded from family members who are responsible for shopping out to all family members, especially those who are skilled in online searching and transaction. The main body of consumers also becomes younger. On the other hand, in terms of career choice, the rise of the Internet has led to the emergence of some new vocational types. The choice set is no longer confined to traditional fields. Instead, professions like online translation, food taster, sleep taster and online anchor are not only favored by young people, but also recognized by the society. In July 2020, the Ministry of Human Resources and Social Security officially announced to the public nine new professions, namely "Block Chain Engineering Technician", "Urban Management Grid Worker", "Internet Marketing Technician", "Information Security Tester", "Block Chain Application Operator", "Online Learning Service Technician", "Community Health Assistant", "Elderly Capacity Appraiser" and "Material Enhancement Manufacturing Equipment Operator". Among them, the "Internet marketing Technician" includes "live salesman" under the occupation, which means ecommerce anchors and online celebrities who sell goods now also have official professional titles.

\subsection{New organizations}

The network externalities and other characteristics of the Internet have laid a foundation for the emergence of new forms of production and consumption organizations. From the perspective of enterprises and production, the Internet has promoted the development of the platform as a networked organization, bringing a revolution to the traditional industrial form, division of labor and organization (Li et al., 2013a, b).

The main features of the Internet platform organization model are the following:

New structure of supply organization: the platform economy can flexibly integrate multiple suppliers, thus being better able to respond quickly to the personalized demands of consumers (Rifkin, 2014). Economic activities in different regions and departments can be integrated on the same digital platform, with a unified hardware, software and management organization replacing the original decentralized economic organization. On this basis, in order to jointly explore the market and jointly deal with other competitors, enterprises with different resources and advantages will organize a kind of enterprise alliance based on information network to share technology and information, share costs, jointly develop and benefit each other, that is, "virtual enterprise". This new type of cross-enterprise organization
Economics' view of the Internet 
$\underset{1,1}{\text { JIDE }}$

8

is more sensitive to changes in the market and technology due to its high liquidity of resources and flexible profit sharing and risk sharing mechanism. It can integrate various resources in a relatively short period of time at a relatively low cost due to a strong openness and flexibility (Martinez et al., 2001).

New structure of circulation organization: the platform organization has significantly reduced the friction cost of circulation through unified back-office allocation based on big data and efficient and smart logistics systems. Platform organizations have outweighed nonplatform organizations in many fields, for example, e-commerce platforms such as Amazon, Taobao and Jingdong have rejected the traditional layer-by-layer price increase sales model, which in turn expands the market scope and transaction depth.

New structure of employment organization: through the platform and algorithm, the supply and demand sides of the labor market are matched efficiently, which makes it possible to organize large-scale demand-based "crowdsourcing" and then forms new labor supply organization patterns characterized as gig economy or sharing economy (Gandini, 2019). However, we should claim that the monopoly tendency of Internet platforms may affect social welfare. Nuccio and Guerzoni (2018) find that the Internet economic platform has the advantage of first-mover but makes it very difficult for the latter to enter. Therefore, anti-monopoly policies are needed to ensure full competition among the platforms. From the perspective of individual consumption, new organizational forms have been formed under the Internet economy such as "producers and consumers" and "fan economy". In the sharing economy, traditional enterprise can no longer exist. In the "supplier-sharing platformconsumer" relationship dominated by platform companies, consumers and suppliers can exchange roles at any time. As consumers of goods or service, users are also producers of platform data and content (Ritzer et al., 2012). The "fan economy" refers to the social capital platform and commercial operation behavior with fans as the main body and based on a certain trust relationship. Through the demonstration effect of stars, consumers will be leaded to produce irrational preferences for certain products and services. Such preference will form an organized and targeted community and generate a "fan economy" effect (Cai, 2015).

\subsection{New space}

The Internet opens up a wider space for economic activities and makes the flow of elements in the space smoother.

First, the Internet provides a virtual space for the network. Internet virtual space plays an important role in social interaction at individual level, social expression at group level and social differentiation at macro level. For example, the Internet has changed the trading place, and the supply side and the demand side of products can freely enter virtual places such as e-commerce platforms to realize online commodity trading across spatial constraints (Goldfarb and Tucker, 2019).

Second, the Internet has expanded the existing space-time boundaries. Castells (2011) points out that the emergence of the network has achieved the connection between virtual and real spaces, making it possible for information to flow in a timely manner around the world, forming a special form of space-flowing space, thus realizing the geographical extension of social activities. In terms of time, different from mechanical time and biological time in the traditional sense, social time with relativity is generated under the background of network society, and thus social time and space connected with each other are constructed.

The intervention of the Internet has reduced the cost of the intermediate links in production, truly realizing point-to-point and end-to-end direct access and greatly shortening the operation time of each product from research and development, manufacturing to marketing. Finally, the Internet has broken the inherent time and space constraints. 
The evidence includes the following: (1) the time and space restriction of communication between individuals is broken. Through various online communication spaces such as online communities, instant messaging tools, e-mail and e-commerce platforms, people can freely communicate with each other, asking questions and getting answers and sharing personal experience about certain product or service. (2) The time and space constraints of the interaction between individuals and enterprises are broken. For example, consumers can conduct online search, purchase, payment and commodity evaluation anytime and anywhere, while enterprise employees can realize telecommuting through the networked mobile office system. (3) The time and space constraint of the supply chain is broken. The platform of supply chain information enables enterprises located in different regions to realize the interaction of product order information, enables module suppliers to produce and deliver products in real time and shortens the product turnaround time together with system integrators (Cheng, 2013).

\subsection{New structure}

With the advent of the digital age, the traditional social and economic structure is also undergoing a transformation. From the perspective of economic structure, the Internet has promoted the optimization and upgrading of industrial structure.

In agriculture, the Internet promotes the integration of modern information technology and agriculture and is changing the traditional production and operation pattern of agriculture. Digital agriculture has become the development direction of agriculture in the future (Li, 2015). In the manufacturing industry, the Internet has optimized the structure of both supply and demand sides of the manufacturing industry, significantly easing the information asymmetry between production and sales of the manufacturing industry and accelerating the close connection between the production side and the market demand side (Shi and $\mathrm{Li}, 2020$ ). In the service industry, the integration of the Internet with the traditional service industry has spawned a large number of emerging industries, such as online shopping, online games, online car rental, online education, etc.

From the perspective of social structure, the Internet is making the traditional social structure undergo a revolution of deconstruction and reconstruction, forming a brand-new social relationship and social operation model (Li et al., 2013a, b).

The use of the Internet is accelerating the change of the dual structure of urban and rural areas and promoting rural economic and social development. The popularity of the Internet in the rural areas has broken the long-standing situation of information blocking in the rural areas, eased the information asymmetry between the urban and rural areas due to factors such as transportation and location and will enable the rich resources in the rural areas to be discovered and utilized as never before. Also, the Internet has broken the imbalanced status of one-way flow of urban and rural resource allocation. For a long time, regardless of natural resources, high-quality agricultural products or young and middle-aged labor force, the flow of resources between urban and rural areas has been dominated by one-way flow from rural areas to cities. Now this unfair situation has begun to ease with the popularity of the Internet in rural areas (Cheng and Zhang, 2019). For example, the development of e-commerce has greatly expanded the space for rural entrepreneurship and is attracting a large number of workers to return hometown for entrepreneurship.

The Internet is also changing the traditional structure of social relationship. Under the environment of the Internet, social individuals can participate in the economy and society in various ways. Information is exchanged more fully in the market, and the nodes of information dissemination grow explosively, which enhance the self-media and e-community to promote the openness and transparency of social governance and government regulation. As an essential tool to maintain social relations, social media is growing into the key channel

Economics'

view of the

Internet 
JIDE

for organizations to communicate with their employees, customers, partners and other stakeholders. "Online" has become a basic way of social interaction, and information release platforms and social media platforms are replacing the traditional methods and channels of information transmission. It should be noticed that although the Internet helps to expand social relationship network, it may also bring some negative effects to social interaction, such as group differentiation and interpersonal isolation in the real world (Sabatini and Sarracino, 2017). Especially for the teenagers who are addicted to the Internet, the Internet brings them into a novel world but interferes with their normal socialization.

\subsection{New systems}

To keep up with the pace of the development of digital economy, the construction of Internetrelated systems is also making new progress. These systems cover the strategic planning of Internet development, network information governance, network security, digital currency and electronic payment, innovative financial supervision, protection of network intellectual property rights, new business forms, management of products and services and other areas. At the strategic level, the Chinese government has explicitly proposed in the 14th Five-Year Plan and other documents to promote the deep integration of the digital economy and the real economy; Strengthen the construction of digital society and digital government and improve the level of digital intelligence in public service and social governance; Establishing basic systems and standards for the property rights, transaction circulation, cross-border transmission and security protection of the data; Safeguarding national data security and strengthening personal privacy protection; Improving the digital skills of the society, etc.

Specifically, governments of various countries are accelerating the establishment and improvement of various regulatory systems involving platform anti-monopoly, Internet financial supervision, Internet intellectual property protection, Internet security and Internet information governance (Beaumier et al., 2020). For example, in terms of platform antimonopoly, according to the fact that monopoly agreements in the platform economy are more covert and the use of data, algorithms and platform rules makes it more difficult to search and judge monopoly agreements, the Chinese government issued the Anti-monopoly Guide on the Platform Economy in early 2021, specifically expanding the scope of application of the traditional anti-monopoly law to the platform economy. It covers the determination of market dominance, unfair pricing behavior, sales below cost, restricted transactions, differential treatment, tying or attaching unreasonable transaction conditions, and many well-known phenomena such as "either-or" and "price discrimination based on big data" can be determined as abuse of market dominance.

In terms of financial supervision, the application of big data, artificial intelligence, distributed accounting and other technologies in the financial field has spawned a number of new financial technology business patterns, products and services. The financial management department has made great efforts to improve the supervision of the FinTech activities and has made active explorations in clarifying technical guidelines, raising regulatory standards and improving regulatory methods (Yang, 2018). On the one hand, it is necessary to strengthen the restriction and guidance of technology. It mainly involves application principles, technical requirements, risk prevention and control and data security. For example, the central bank of the Netherlands issued "general principles for the application of artificial intelligence in financial industry (draft for comments)" in July 2019; In February 2019, the Central Bank of Russia issued "Information Security Recommendations for Biometric Identification Systems”. On the other hand, it is necessary to improve the regulatory framework and pay attention to risk prevention and control. Financial regulatory authorities in most economies have established the FinTech regulatory frameworks based on the principles of functional regulation and behavioral regulation. For example, the financial 
regulatory authorities in Singapore and Hong Kong, China, have set up special digital banking licenses, which require applicants to meet certain access standards and comply with risk-based capital requirements.
Economics'

view of the

Internet

\subsection{New norms}

The rapid development of the digital economy has profoundly affected the economic behavior and thinking mode of each participant, forming new norms with the characteristics of Internet economy. In terms of business operation, two typical new cases are work-from-home and gig economy. By the end of June 2020, the number of telecommuting users in China had reached about 200 million, accounting for $21.2 \%$ of the total number of Internet users. During the COVID-19 epidemic, the use of Zoom videoconferencing services increased tenfold (Branscombe, 2020). As employees gradually adapt to home-based meetings and work, more and more enterprises regard work-from-home as a norm rather than a special case (Bai et al., 2021).

The "gig economy" is a business pattern mainly implemented by online platforms, which generally employ part-time crowdsourcing to hire staff on a temporary, short-term and informal basis. The gig economy is essentially an Internet technology-driven change in work patterns, a new specification relying on platforms and algorithms (De Stefano, 2015), which is more suitable to the trend of broad and flexible labor market participation and has the characteristics of increasing uncertainty, separation of paid work from fixed jobs and increasingly dispersed tasks in the supply chain and projects (Stewart and Stanford, 2017). In terms of market transactions, reputation has been commonly recognized as the basic norm in the online market, motivating the platforms to guarantee the quality of their products. Although some sellers are "short-term" players and the incentives to build reputation may be low, the platform, as a "long-term" player, has stronger motivation and more responsibility to build and maintain reputation (Tadelis, 2016).

Most of the transactions in the platform economy are small and cross-regional, and it is very difficult to safeguard rights and regulate through the traditional system. Nowadays, almost all the platform-based enterprises have established a reputation standard evaluation system to deal with the information asymmetry and other issues. Reputation management not only affects the transaction price and volume, but also becomes a prerequisite for many transactions. Users can predict the risks of the transaction based on the feedback information of the historical transaction and then decide whether to carry out the transaction, which makes it difficult for participants with bad behaviors to continuously survive in the market.

Further, reputation management can also be used to differentiate users, so that superior users would be identified while inferior users would be eliminated. In terms of residents' living, one example of the new norm is electronic payment. Consumers are getting used to trading with electronic money instead of traditional money. In China, the substitution of new electronic money for cash has been increasing year by year since 2011. By 2016, the scale of substitution was estimated to be more than 1.3 trillion yuan, accounting for approximately $20 \%$ of the total cash flow in the country (Leon, 2018). The influence of digital payment method on residents' daily behavior is significant. For instance, on Chinese New Year's Eve in 2020, more than 800 million people used WeChat electronic red packet to send money, which has become a new folk custom.

The norm of sharing also results from the development of the Internet economy. Hamari et al. (2016) summarize that the incentives for consumers to participate in sharing include cost saving, trust in other users, ecological sustainability and modern lifestyle. The main characteristics of sharing norms are the following: (1) collaborative consumption. The core is to meet users' specific needs through sharing and exchange, but ownership does not transfer.

(2) Trust. The establishment of trust in strangers is a prerequisite for the existence of sharing 
JIDE

behavior and is also a typical feature of sharing consumption pattern. (3) Economy. By allowing multiple users to temporarily rent those formerly underutilized physical assets by turns, it effectively reduces people's cost of living.

\section{Conclusion}

At last, looking forward to the future, how to promote the research on the Internet and digital economics deserves our in-depth thinking.

I strongly agree with the view of an economic history scholar, Professor Wu Chengming, who argued that "economic history is rather the source than the flow, and there are no fixed methods to figure out history". In my opinion, when the Internet and digital economy evolves into the general economic form of our society in the future, it must also be the source of our research questions, rather than a branch school. Since, the Internet economics is the source, the methods to study it should be as diverse as "a hundred flowers blossom and a hundred schools of thought contend", instead of rigidly adhering to a fixed method. In a word, research on the Internet and digital economics should be based on reality and problem-oriented.

\section{References}

Akerman, A., Gaarder, I. and Mogstad, M. (2015), "The skill complementarity of broadband internet", The Quarterly Journal of Economics, Vol. 130 No. 4, pp. 1781-1824.

Bai, J., Brynjolfsson, E., Wang, J., Steffen, S. and Wan, C. (2021), "Digital resilience: how work-fromhome feasibility affects firm performance", National Bureau of Economic Research, No. w28588.

Barrett, M., Davidson, E., Prabhu, J. and Vargo, S.L. (2015), "Service innovation in the digital age", MIS Quarterly, Vol. 39 No. 1, pp. 135-154.

Beaumier, G., Kalomeni, K., Campbell-Verduyn, M., Lenglet, M., Natile, S., Papin, M., Rodima-Taylor, D., Silve, A. and Zhang, F. (2020), "Global regulations for a digital economy: between new and old challenges", Global Policy, Vol. 11 No. 4, pp. 515-522.

Bogan, V. (2008), "Stock market participation and the internet", Journal of Financial and Quantitative Analysis, Vol. 43 No. 1, pp. 191-211.

Branscombe, M. (2020), "The network impact of the global COVID-19 pandemic", The New Stack, available at: https://thenewstack.io/the-network-impact-of-the-global-covid-19-pandemic/.

Cai, Qi (2015), "Fan economic pattern in the era of social network", China Youth Studies, Vol. 11, pp. 5-11.

Castells, M. (2011), The Rise of the Network Society, John Wiley \& Sons, Hoboken, New Jersey.

Chechina, O.S. and Nikonorova, S.A. (2019), "The impact of the digital economy on the quality of life", Digital Economy: Complexity and Variety Vs. Rationality, Vol. 87, p. 417.

Cheng, L. (2013), "Research on enterprise value network innovation under internet economy", China Industrial Economics, Vol. 9, pp. 82-94.

Cheng, M. and Zhang, J. (2019), "Internet popularization and urban-rural income gap: theory and empirical analysis", China Rural Economy, Vol. 2, pp. 19-41.

Choi, H. and Varian, H. (2012), "Predicting the present with google trends", Economic Record, Vol. 88, pp. 2-9.

Chopik, W.J. (2016), "The benefits of social technology use among older adults are mediated by reduced loneliness", Cyberpsychology, Behavior and Social Networking, Vol. 19 No. 9, pp. 551-556.

De Stefano, V. (2015), "The rise of the just-in-time workforce: on-demand work, crowd work, and labor protection in the gig-economy", Comparative Labour Law and Policy Journal, Vol. 37, p. 471. 
Dillon, S.M., Glavas, C. and Mathews, S. (2020), "Digitally immersive, international entrepreneurial experiences", International Business Review, Vol. 29 No. 6, 101739.

$\mathrm{Du}, \mathrm{L}$. and Cheng, J. (2020), "The historical evolution of economic methodology and the development trend of artificial intelligence era", New Horizon, Vol. 5, pp. 110-117.

Gandini, A. (2019), "Labour process theory and the gig economy", Human Relations, Vol. 72 No. 6, pp. 1039-1056.

Goldfarb, A. and Tucker, C. (2019), "Digital economics", Journal of Economic Literature, Vol. 57 No. 1, pp. 3-43.

Grabner-Kraeuter, S. (2002), “The role of consumers' trust in online-shopping”, Journal of Business Ethics, Vol. 39 No. 1, pp. 43-50.

Hamari, J., Sjöklint, M. and Ukkonen, A. (2016), "The sharing economy: why people participate in collaborative consumption", Journal of the Association for Information Science and Technology, Vol. 67 No. 9, pp. 2047-2059.

Horton, J.J. and Zeckhauser, R.J. (2016), "Owning, using and renting: some simple economics of the sharing economy", National Bureau of Economic Research, No. w22029.

Huang, Y., Wang, M., Fu, Q. and Zhang, H. (2018), "Reconstructing China's rural finance with marketization, industrialization and digitalization strategies", International Economic Review, Vol. 3, pp. 106-124.

Jiang, X. (2017), "Resource restructuring and service industry growth in highly connected society", Economic Research Journal, Vol. 3, pp. 4-17.

Katz, J.E. and Rice, R.E. (2002), Social Consequences of Internet Use: Access, Involvement, and Interaction, MIT Press, Cambridge, Massachusetts.

Kroft, K. and Pope, D.G. (2014), "Does online search crowd out traditional search and improve matching efficiency? Evidence from Craigslist", Journal of Labor Economics, Vol. 32 No. 2, pp. 259-303.

Leon, W. (2018), "An empirical study on the effect of electronic money on cash substitution from the perspective of third-party payment", Shanghai Finance, Vol. 6, pp. 87-92.

Leung, L. and Lee, P.S. (2005), "Multiple determinants of life quality: the roles of internet activities, use of new media, social support, and leisure activities", Telematics and Informatics, Vol. 22 No. 3, pp. 161-180.

Levin, J.D. (2011), "The economics of internet markets", National Bureau of Economic Research, No. w16852.

Li, G. (2015), "Deconstruction of China's modern agricultural industry chain and business pattern under the background of "internet plus", Rural Economy, Vol. 9, pp. 29-33.

Li, Q., Liu, Q. and Chen, Y. (2013a), "Internet's influence on society and its construction ideas”, Beijing Social Sciences, Vol. 1, pp. 4-10.

Li, Y., Liu, H. and Huang, S. (2013b), "Research trends of platform economy theory", Economic Perspectives Journal, Vol. 7, pp. 123-129.

Lu, Y. and Wang, J. (2020), "Digital divide or information welfare? - the impact of internet use on residents' subjective welfare”, Economic Perspectives Journal, Vol. 2, pp. 59-73.

Martinez, M.T., Fouletier, P., Park, K.H. and Favrel, J. (2001), "Virtual enterprise-organization, evolution and control", International Journal of Production Economics, Vol. 74 No. 1-3, pp. 225-238.

Meng, T. and Huang, D. (2019), "Revisiting responsive government: diversity and institutional performance of online politics", Social Sciences in China, Vol. 40 No. 4, pp. 148-172.

Mossberger, K., Tolbert, C.J. and McNeal, R.S. (2007), Digital Citizenship: The Internet, Society, and Participation, MIT Press.
Economics'

view of the

Internet 
$\underset{1,1}{\text { JIDE }}$

Naudé, W. and Liebregts, W. (2020), "Digital entrepreneurship research: a concise introduction", IZA Discussion Papers.

Nuccio, M. and Guerzoni, M. (2018), "Big data: hell, or heaven? Digital platforms and market power in the data-driven economy", Competition and Change, Vol. 23 No. 3, pp. 312-328.

Rifkin, J. (2014), The Zero Marginal Cost Society: The Internet of Things, the Collaborative Commons, and the Eclipse of Capitalism, St. Martin's Press, New York, New York.

Ritzer, G., Dean, P. and Jurgenson, N. (2012), "The coming of age of the prosumer", American Behavioral Scientist, Vol. 56 No. 4, pp. 379-398.

Sabatini, F. and Sarracino, F. (2017), "Online networks and subjective well-being”, Kyklos, Vol. 70 No. 3, pp. 456-480.

Shi, B. and Li, J. (2020), "Does the internet promote division of labor: evidence from Chinese manufacturing firms", Journal of Management World, Vol. 36 No. 4, pp. 130-149.

Stewart, A. and Stanford, J. (2017), "Regulating work in the gig economy: what are the options?", The Economic and Labour Relations Review, Vol. 28 No. 3, pp. 420-437.

Sun, K., Wang, D. and Xiao, X. (2020), "Internet information environment renovation and the corporate governance role of social media”, Journal of Management World, Vol. 36 No. 7, pp. 106-132.

Tadelis, S. (2016), "Reputation and feedback systems in online platform markets", Annual Review of Economics, Vol. 8, pp. 321-340.

Varian, H.R. (2010), "Computer mediated transactions", American Economic Review, Vol. 100 No. 2, pp. 1-10.

Wang, Y. (2019), "Does e-commerce participation enhance farmers' economic sense of achievement? difference between poor households and non-poor households", China Rural Economy, Vol. 7, pp. 37-50.

Wang, D. and Wang, H. (2016), "The rise of mobile internet and social changes", Social Sciences in China, Vol. 7, pp. 105-112.

Yang, D. (2018), "Regulatory technology: regulatory challenges and dimension construction of financial technology", Social Sciences in China, Vol. 5, pp. 69-91.

Zhang, S. (2011), "Draw a clear line between information and knowledge-study information economy and knowledge economy separately", Economic Perspectives Journal, Vol. 10, pp. 33-37.

Zhou, G. and Zhou, X. (2001), "The impact of the internet on the state and the state's response", Journal of Political Science, Vol. 2, pp. 37-46.

\section{Corresponding author}

Li Tao can be contacted at: litao@cufe.edu.cn

For instructions on how to order reprints of this article, please visit our website:

www.emeraldgrouppublishing.com/licensing/reprints.htm

Or contact us for further details: permissions@emeraldinsight.com 